Research Article

\title{
Effect of Additives on the Rheological and Mechanical Properties of Microfine-Cement-Based Grout
}

\author{
Shuai Zhang $\mathbb{D}^{1,2}$ Weiguo Qiao $\mathbb{D}^{1,{ }^{1,2}}$ Yanzhi Li $\mathbb{D}^{1,2}$ Kai Xi, ${ }^{1,2}$ and Pengcheng Chen ${ }^{1,2}$ \\ ${ }^{1}$ Shandong Provincial Key Laboratory of Civil Engineering Disaster Prevention and Mitigation, \\ Shandong University of Science and Technology, Qingdao, China \\ ${ }^{2}$ College of Civil Engineering and Architecture, Shandong University of Science and Technology, Qingdao, China \\ Correspondence should be addressed to Weiguo Qiao; qiaowg1@163.com
}

Received 23 February 2019; Revised 3 June 2019; Accepted 4 July 2019; Published 27 August 2019

Academic Editor: Viviana F. Rahhal

Copyright (c) 2019 Shuai Zhang et al. This is an open access article distributed under the Creative Commons Attribution License, which permits unrestricted use, distribution, and reproduction in any medium, provided the original work is properly cited.

Enhancement of the fluidity and mechanical performance of grouting materials has proven to be an effective method of seepage prevention in geotechnical engineering. In this research, a microfine-cement-based grout mixed with microfine fly ash (MFA), nano- $\mathrm{CaCO}_{3}(\mathrm{NC})$, and superplasticizer (SP) was designed to improve the rheological and mechanical properties of grouting materials, and the particle size distribution, fluidity, spreading ability, bleed capacity, setting time, and mechanical properties were studied. A water/solid (W/S) ratio of 1.2 was selected, and the contents of MFA, NC, and SP by mass of microfine cement (MC) were $0-40 \%, 0-2.0 \%$, and $1.5 \%$, respectively. The results showed that MFA and $1.5 \%$ SP improved the fluidity and spreading ability of fresh grouts, while prolonging the setting time. The addition of NC can increase the yield stress and plastic viscosity and decrease the fluidity and spreading ability; nevertheless, it obviously enhances the stability and shortens the setting time of grouts. The addition of MFA and 1.5\% SP reduced the compressive strength of hardened grouts; however, the addition of NC improved the mechanical properties.

\section{Introduction}

To ensure the safe construction and operation of structures, a high-performance grouting material is required to improve the mechanical properties and behavior of rocks or soils by permeation grouting [1]. Cement-based grouts and chemical grouts are the most commonly used grouting materials in grouting engineering. Chemical grouts have the advantages of low viscosity and good injection ability, and they can be injected into fine sands or microfractures. However, chemical grouts not only pose a health and environmental hazards but are also more expensive. Therefore, microfine cement (MC) grouts have been developed in recent years to expand the application scope of cement grouts and to replace harmful chemical grouts in grouting engineering. Mollamahmutoglu and Avci [2] investigated the grouting performance of ultrafine cement in various fine- and mediumgrade sands and found that ultrafine cement grouts with dispersive agents could successfully penetrate fine sands.
Pantazopoulos et al. [3] reported that the pulverization of ordinary Portland cement to produce ultrafine cement has a positive effect on mechanical strength and groutability but a detrimental effect on viscosity. Considering the poor stability and long setting time of pure cement grouts, supplementary cementitious materials are being increasingly used in MC grouts to improve their performance [4]. Assaad and Gerges [5] studied the effect of styrene-butadiene rubber on fresh grout properties (rheology, bleeding, and washout loss) and found that the addition of styrene-butadiene rubber could improve the fresh states of grouts. This result was attributed to the fact that styrene-butadiene rubber could coalesce in the cementitious matrix and increase the viscosity of the interstitial liquid phase.

As a common additive to cement-based grouts, MFA can react with calcium hydroxide $(\mathrm{CH})$ due to the presence of $\mathrm{SiO}_{2}$ and $\mathrm{Al}_{2} \mathrm{O}_{3}$ and generate additional calcium silicate hydrate $(\mathrm{CSH})$ gel [6]. This pozzolanic effect improves the performance of grouts, but the use of MFA as an additive is 
generally limited to $40 \%$ by mass of cement to avoid a long setting time and a low early strength. Li et al. [7] investigated the viscous behavior and strength of microfine-cementbased gouts and found that the addition of $40 \%$ MFA could remarkably prolong the setting times and decrease the compressive strength. Sha et al. [8] found that class F FA could enhance the flowability and spreading ability of cement-based grouts, but reduce the stability of fresh grouts. Because of electrostatic interactions and humidity, MC particles agglomerate together. To overcome this limitation, $\mathrm{SP}$ is selected to decrease interparticle attractive forces and enhance full wetting of the cement particles during mixing; therefore, it can improve the fluidity of grouts due to its water reducing effect. Laichaoui et al. [9] studied the effect of the superplasticizer type on the properties of cementitious systems and found that polycarboxylate superplasticizers are more effective in improving workability and reducing viscosity and yield stress than polynaphthalene superplasticizers. Mollamahmutoglu and Yilmaz [10] studied the penetrability of microfine cement grouts mixed with and without superplasticizer into fine-to-medium sands and noted that the addition of SP significantly improves the grouting performance and reduces the grouting pressure. Mollamahmutoglu and Yilmaz also found that the unconfined compressive strength of sand specimens grouted with microfine cement grouts is reduced by the addition of superplasticizer.

Nanomaterials such as nano- $\mathrm{SiO}_{2}$, nano- $\mathrm{Al}_{2} \mathrm{O}_{3}$, nano- $-\mathrm{TiO}_{2}$, and nano- $\mathrm{CaCO}_{3}$ are widely added to concrete because they improve the mechanical properties and durability of the concrete. Calcium carbonate can be obtained from marble and limestone or synthesized by combining calcium with carbon dioxide [11]. Sato and Beaudoin [12] and Supit and Shaikh [13] found that the addition of NC significantly accelerated the early hydration of ordinary Portland cement and that the acceleration improved with increasing NC content. Supit and Shaikh [13] stated that the early age and the 28-day compressive strength of high-volume fly ash concretes increased by adding NC particles. Yang and Che [14] experimentally showed that NC/limestone powder reduced porosity and enhanced pore structure for cementitious materials.

However, limited research has been carried out to investigate the synergistic effect of NC, MFA, and SP in MC grouts on the hydration process and mechanical properties of grouts, especially concerning rheological behavior. This research investigated the performance of microfine-cementbased grouts mixed with MFA, NC, and SP. For this purpose, the effect of MFA, NC, and SP as additives on the rheological and mechanical properties of grouts was studied. In addition, the rheological properties (apparent viscosity, yield stress, and plastic viscosity), fresh states (flow time, minislump, bleed capacity, and setting time) and mechanical properties (flexural and compressive strength) were characterized.

\section{Materials and Methods}

2.1. Materials. In this research, the MC and MFA were obtained by dry grinding of ordinary Portland (type I-42.5 MPa) cement and class F fly ash, respectively. The
NC was provided by a cooperated company in Beijing and had an average particle diameter of $30 \mathrm{~nm}$. The chemical compositions of MC, MFA, and NC are listed in Table 1. The Blaine fineness values of MC, MFA, and NC were $920 \mathrm{~m}^{2} / \mathrm{kg}$, $1033 \mathrm{~m}^{2} / \mathrm{kg}$, and $4000 \mathrm{~m}^{2} / \mathrm{kg}$, respectively. In this research, a polycarboxylate superplasticizer was used to improve the grout properties, and the properties of SP are shown in Table 2. Moreover, potable water was used to prepare all grouts, and the ambient temperature was $20 \pm 2^{\circ} \mathrm{C}$.

2.2. Preparation of Microfine-Cement-Based Grouts. Initially, for fresh grouts with SP, the $1.5 \%$ SP was mixed with the calculated amount of water by a cement mixer at $240 \mathrm{rpm}$ for two min. Then, MC, MFA, and NC were added, and the fresh grouts were mechanically stirred by the cement mixer at a high-speed of $1000 \mathrm{rpm}$ for five min to ensure their uniformity. This procedure was recommended by the SP manufacturer. The contents of MFA, NC, SP by mass of MC and $\mathrm{W} / \mathrm{S}$ ratio in this research were $0-40 \%, 0-2.0 \%, 1.5 \%$, and 1.2 , respectively. For fresh grouts without SP, the mixing speed was $1000 \mathrm{rpm}$ by the cement mixer for seven min.

2.3. Experimental Methods. The viscosity of grouts was tested using an NDJ-8S rotational viscometer for viscosity measurements between 1 and $6 \times 10^{6} \mathrm{MPa} \cdot \mathrm{s}$. The viscometer has nine rotation speeds: $0.1,0.3,0.6,1.5,3,6,12,30$, and $60 \mathrm{rpm}$. Immediately after preparation, the fresh grouts were placed in a $400 \mathrm{~mL}$ beaker with a diameter of $77 \mathrm{~mm}$, and then the viscosity values were measured (time from preparation equal to $0 \mathrm{~min}$ ). The viscometer shows an apparent viscosity when fresh grouts are non-Newtonian, and the measurements were taken at predetermined time intervals of $15,30,60,90$, and $120 \mathrm{~min}$.

The fluidity of fresh grouts was commonly represented by the flow time and measured by a Marsh funnel $[15,16]$. The internal orifice diameter of the Marsh funnel was $4.8 \mathrm{~mm}$, and it was filled with $1500 \mathrm{~mL}$ of fresh grout after preparation. The time required for $946 \mathrm{~mL}$ of fresh grout to flow through the Marsh funnel was defined as the flow time in this study. Note that the flow time of $946 \mathrm{~mL}$ of potable water is approximately $26 \pm 0.5 \mathrm{~s}$. The mini-slump test can be expressed as the spreading ability of fresh grouts $[17,18]$. The fresh grouts were placed in a cone mold on a glass plate, and then the cone mold was lifted in the vertical direction. The spreading diameter of fresh grouts at $30 \mathrm{~s}$ was tested; specifically, the cone mold dimensions were $60 \mathrm{~mm}$ in height, $60 \mathrm{~mm}$ in top diameter, and $36 \mathrm{~mm}$ in bottom diameter.

Bleed capacity was tested by conducting sedimentation tests, and the bleed capacity was defined as the final value of $\Delta V / V_{0}$, where $\Delta V$ is the volume of bleed water and $V_{0}$ is the initial volume of fresh grouts [19-21]. The fresh grouts were placed in a $1000 \mathrm{~mL}$ graduated cylinder for $2 \mathrm{~h}$, and the volume of excess water was measured at $30 \mathrm{~min}$ intervals until sedimentation was complete.

According to ASTM Standard C191 [22], the initial and final setting times were measured by conducting Vicat needle tests. Note that the excess water was removed after 
TABle 1: Chemical compositions of MC, MFA, and NC (wt.\%).

\begin{tabular}{lccccccccccc}
\hline Materials & $\mathrm{CaO}$ & $\mathrm{SiO}_{2}$ & $\mathrm{Al}_{2} \mathrm{O}_{3}$ & $\mathrm{Fe}_{2} \mathrm{O}_{3}$ & $\mathrm{MgO}$ & $\mathrm{Na}_{2} \mathrm{O}$ & $\mathrm{K}_{2} \mathrm{O}$ & $\mathrm{TiO}_{2}$ & $\mathrm{SO}_{3}$ & $\mathrm{CaCO}_{3}$ & $\mathrm{LOI}^{2}$ \\
\hline MC & 62.51 & 21.53 & 4.08 & 2.89 & 3.31 & 0.21 & 0.57 & 0.30 & 3.04 & - \\
MFA & 3.98 & 40.55 & 17.83 & 28.98 & 1.56 & 0.98 & 1.43 & 0.93 & 1.32 & - \\
$\mathrm{NC}$ & - & - & - & 0.03 & 0.5 & - & - & - & - & 98.5 \\
\hline
\end{tabular}

Table 2: Properties of SP used in this research.

\begin{tabular}{lccccc}
\hline Aspect & Specific gravity & $\mathrm{pH}$ & Chloride ion content & Solid content (\%) & Molecular mass (g/mol) \\
\hline Light yellow & 1.08 & $6-7$ & Chloride free & 40 & 42000 \\
\hline
\end{tabular}

each 30 min interval, leaving the cell full of sediment after the completion of bleeding.

The 28-day unconfined compressive strength of hardened grouts was measured according to GB/T 17671 [23]. The specimen size for compressive strength was $40 \times 40 \times 160 \mathrm{~mm}$, and the loading rate was $0.3 \mathrm{~mm} / \mathrm{min}$. According to ASTM C78-16 [24], the 28-day flexural strength of hardened grouts was measured, the dimension of specimens was $40 \times 40 \times 160 \mathrm{~mm}$, and the loading rate was $50 \mathrm{~N} / \mathrm{S}$. All specimens were cured in a cement concrete standard curing box held at a temperature of $20 \pm 2^{\circ} \mathrm{C}$ and relative humidity above $95 \%$ for 28 days.

\section{Results and Discussion}

3.1. Grain Size Analysis. According to ISO 13320-1 [25], the grain size distributions of ordinary Portland cement (OPC), $\mathrm{MC}$, and MFA were determined using the laser diffraction technique by an LS900 laser particle size analyzer, which is crucial to assessing the performance of grouting materials. The grain size distributions of MC and MFA are shown in Figure 1.

As shown in Figure 1, with respect to the gradation of MC, $d_{50}, d_{95}$, and $d_{\max }$ of MC were $5.06,12.49$, and $17.46 \mu \mathrm{m}$, respectively. For the grain-size distribution of MFA, $d_{50}, d_{95}$, and $d_{\max }$ were $3.56,7.28$, and $13.74 \mu \mathrm{m}$, respectively. The maximum grain size of MFA was finer than that of MC, and both MFA and MC had a maximum grain size value less than the "microfine" requirements of EN 12715 [26] and other national standards.

3.2. Apparent Viscosity of Fresh Grouts. Grouts should have reasonably low viscosity to ensure satisfactory fluidity and spreading ability. Typical results of apparent viscosity values as a function of time were obtained, for a rotation speed of $60 \mathrm{rpm}$. Figure 2 shows the apparent viscosity values of fresh grouts $(0 \%$ and $1.5 \% \mathrm{SP})$ mixed with different NC contents.

As shown in Figure 2(a), at the W/S ratio of 1.2 , the apparent viscosity values of fresh grouts increased remarkably with an increase in NC contents. When the NC contents were $0 \%, 0.5 \%, 1.0 \%$, and $2.0 \%$, the apparent viscosity ranges of the fresh grouts ( $0 \% \mathrm{SP})$ were $95.3-493.7$, 105.9-625.9, 126.8-700.9, and 150.5-956.3 MPa.s, respectively. In general, the addition of NC, from $0 \%$ to $0.5 \%$, resulted in a small increase of $11 \%$ in the initial apparent viscosity $(0 \mathrm{~min})$ of the fresh grouts. However, addition to a

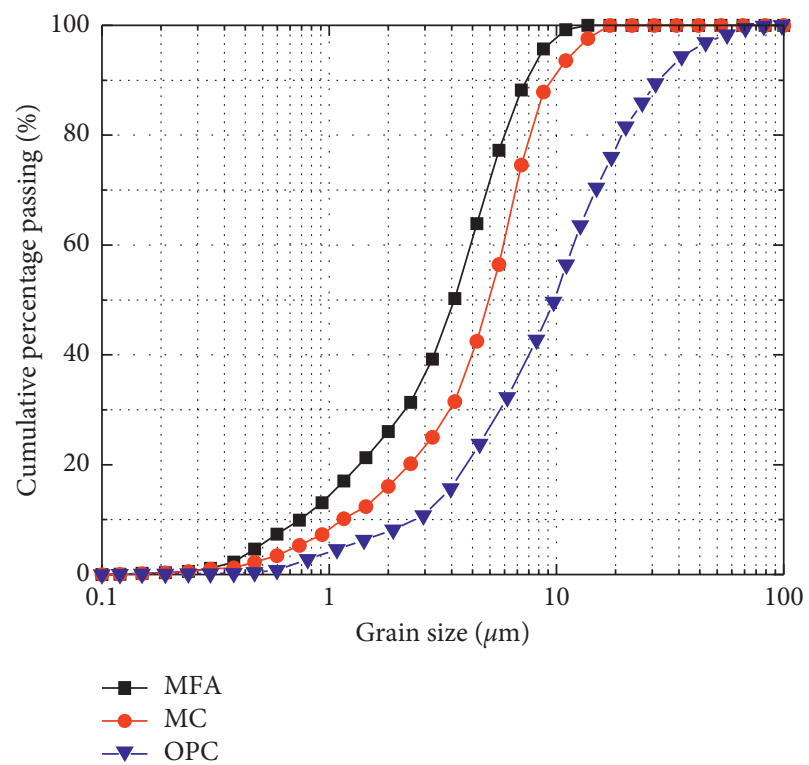

Figure 1: Grain size distributions of MC and MFA.

content of $2.0 \%$ led to a significant increase of $58 \%$ in the initial apparent viscosity. Therefore, the addition of NC had a strong effect on the apparent viscosity of fresh grout. This effect can be attributed to the significant increase (by a factor of 50) in the specific surface area of NC compared to that of $\mathrm{MC}$, which resulted in a remarkable reduction in free water in fresh grouts and an obvious increase in apparent viscosity.

Although there is not a unified limit value, a low viscosity is currently recommended for grouting [27]. Therefore, SP was used to reduce the apparent viscosity for the improvement of slurry fluidity. As shown in Figure 2(b), the apparent viscosity values of fresh grouts obviously decreased with the addition of $1.5 \%$ SP. The decreasing degrees of $1.5 \%$ SP on the initial apparent viscosity values of fresh grouts were $67.8 \%, 66.48 \%, 60.72 \%$, and $57.2 \%$ for NC contents of $0 \%, 0.5 \%, 1.0 \%$, and $2.0 \%$, respectively. These results can be attributed to the fact that the agglomeration of cement particles is eliminated by a combination of electrostatic and steric repulsion; the flocculated structure that can be produced at rest was destroyed by the adsorbed surface of the $\mathrm{SP}$, and therefore, the apparent viscosity was reduced.

Figure 3 shows typical variations in the initial apparent viscosity of fresh grouts with different MFA and NC contents, a W/S ratio of 1.2 , and a SP content of $1.5 \%$. As 


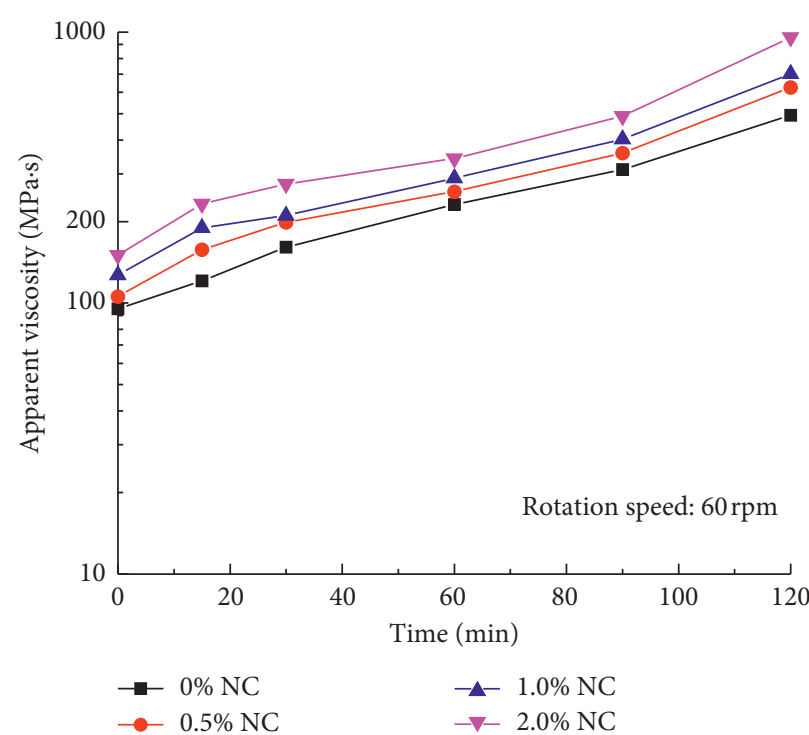

(a)

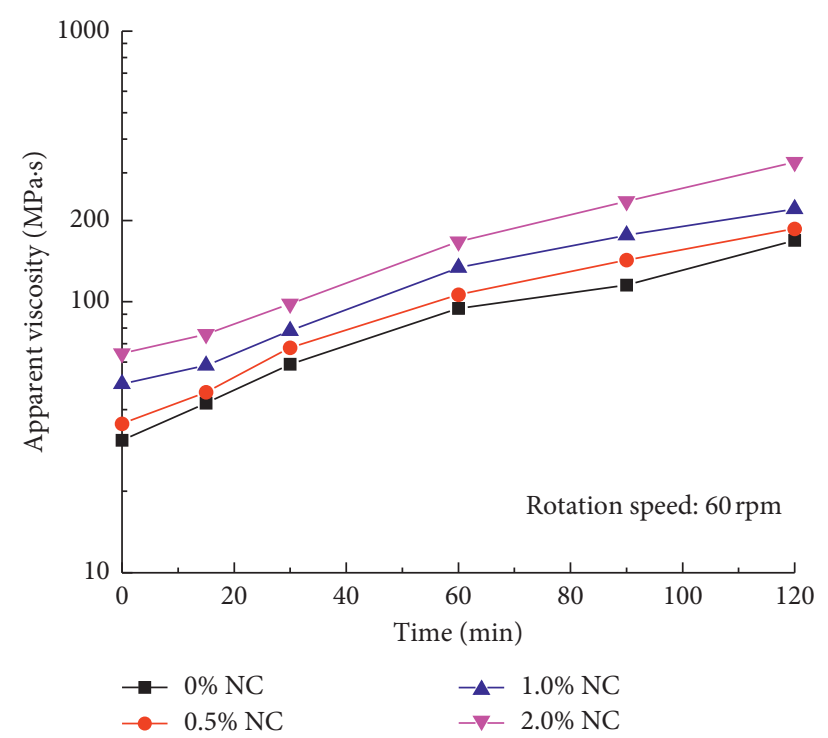

(b)

Figure 2: Apparent viscosity of grouts with different NC contents: (a) $0 \% \mathrm{SP}$; (b) $1.5 \% \mathrm{SP}$.

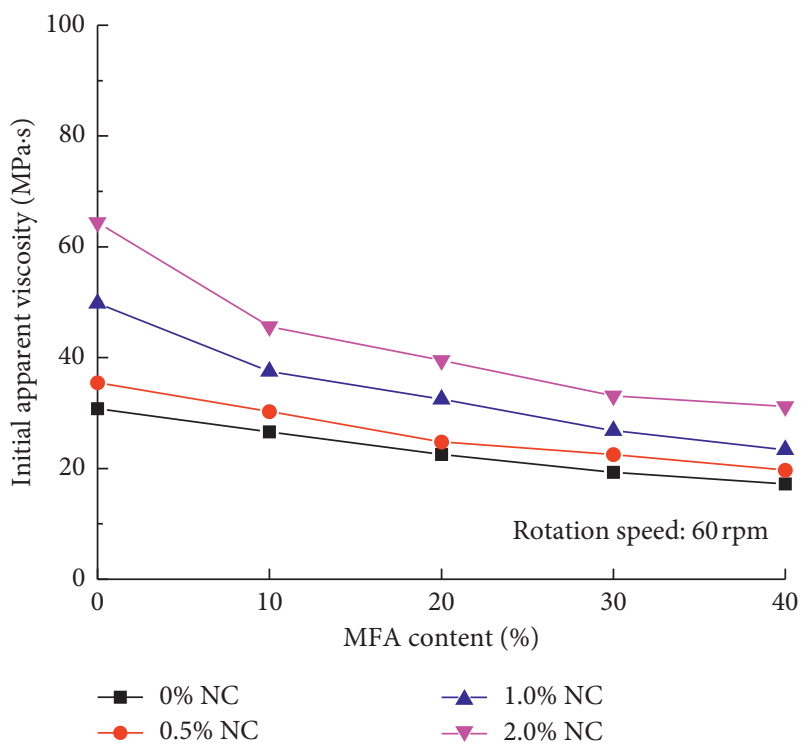

FIGURE 3: Variations in the initial apparent viscosity of fresh grouts with different MFA and NC contents.

illustrated in Figure 3, the initial apparent viscosity values decreased with increasing MFA content, regardless of the NC content. More specifically, when the MFA contents ranged from 0 to $40 \%$, the initial apparent viscosity values of fresh grouts were 30.8-64.4, 26.6-45.6, 22.5-39.5, 19.3-33.1, and 17.2-31.2 MPa.s. Thus, MFA can improve the fluidity of fresh grouts due to "ball effects," as reported in the available literature for cement grouts $[8,9,28]$.

3.3. Yield Stress and Plastic Viscosity. The typical flow curves of fresh grouts (20\% MFA and $1.5 \%$ SP) with NC contents of $0 \%, 0.5 \%, 1.0 \%$, and $2.0 \%$ are presented in Figure 4 . The

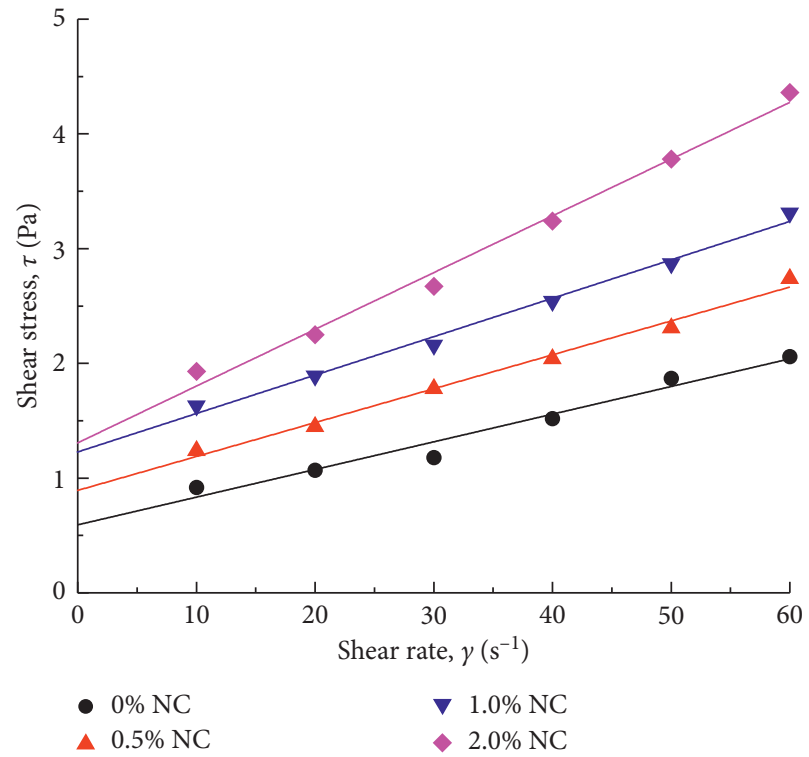

FIgURE 4: Typical flow curves of fresh grouts with different NC contents.

results shown in this figure confirm that the relationship between shear stress and shear rate can be fitted accurately by the Bingham model. The regression equation, rheological parameters of yield stress, and plastic viscosity are presented in Table 3. A high value of regression coefficient $R^{2}$ indicates that the regression results are well correlated with the curve.

Yield stress is the minimum shear stress that drives the grouts to initiate flow and plastic deformation due to the adhesion and friction between the particles of the grouts. Figure 4 and Table 3 demonstrate the effect of NC on the yield stress of fresh grouts. The yield stress of grouts obviously increased after NC was incorporated into grouts to result in the reduced fluidity of the grouts. The yield stress of 
TABLE 3: Rheological properties of fresh grouts.

\begin{tabular}{lcccc}
\hline NC content (\%) & $\mathrm{T}_{0}$ & $\eta$ & Regression equation & $R^{2}$ \\
\hline 0 & 0.59 & 0.024 & $\tau=0.59+0.024 \eta$ & 0.961 \\
0.5 & 0.89 & 0.029 & $\tau=0.89+0.029 \eta$ & 0.988 \\
1.0 & 1.23 & 0.033 & $\tau=1.23+0.033 \eta$ & 0.989 \\
2.0 & 1.31 & 0.049 & $\tau=1.31+0.049 \eta$ & 0.988 \\
\hline
\end{tabular}

$\tau_{0}$ : yield stress $(\mathrm{Pa}) ; \eta$ : plastic viscosity $(\mathrm{Pa} \cdot \mathrm{s})$, and $R^{2}$ : regression coefficient.

fresh grouts with a W/S ratio of 1.2 increased by 51\%, 108\%, and $122 \%$ compared with the control grout $(0 \% \mathrm{NC})$ for $\mathrm{NC}$ contents of $0.5 \%, 1.0 \%$, and $2.0 \%$, respectively. The effect of NC on the yield stress can be explained by two factors. (1) The particle size of NC, as mentioned above, is much smaller than that of cement particles. With the addition of NC, the space between particles decreases due to the filling effect of NC, which increases the opportunity for contact between particles. (2) The specific area of particles in the grouts increases unavoidably because the addition of NC leads to a large amount of water wetting and wrapping the surfaces of the particles. As a result, the frictional force among particles and the flow resistance are enhanced and yield stress increases.

Plastic viscosity is another important parameter that indicates the quantity of microstructures for preventing the flow of grouts. It is mainly influenced by the shape, size, and concentration of particles. The effect of NC content on the plastic viscosity of grouts is shown in Figure 4 and Table 3, revealing that the plastic viscosity increased with increasing NC content. The plastic viscosity of fresh grouts with a W/S ratio of 1.2 increased by $21 \%, 38 \%$, and $104 \%$ compared with the control grout $(0 \% \mathrm{NC})$ for $\mathrm{NC}$ contents of $0.5 \%, 1.0 \%$, and $2.0 \%$, respectively. Because NC particles can absorb water and reduce the number of voids in grouts, the plastic viscosity of grouts with $\mathrm{NC}$ is much larger than that of the control grout. Therefore, the rheological properties of fresh grouts are affected by the addition of NC, and NC can be used as an additive to change the rheological properties of grouts.

3.4. Flow Time of Fresh Grouts. Flow time is also an important parameter for evaluating the fluidity of fresh grouts at side work. The typical flow time results obtained from the Marsh funnel tests are shown in Figure 5.

As shown in Figures 5(a) and 5(b), the addition of NC significantly increased the flow time of fresh grouts; however, the addition of MFA decreased the flow time. When the amounts of NC were $0 \%, 0.5 \%, 1.0 \%$, and $2.0 \%$, the decreases in the flow time of fresh grouts without SP were 3.43-11.58\%, 8.07-17.90\%, 7.82-18.27\%, and 5.74-19.22\% for MFA contents of $10-40 \%$. The addition of $1.5 \%$ SP clearly decreased the flow time of fresh grouts. Notably, the decreasing effect of MFA on the flow time is greatly weakened compared with those of $1.5 \%$ SP. It has been reported that MFA decreases the flow time of fresh grouts, mainly because the "ball effect" of MFA can enhance the fluidity of suspensions.

3.5. Mini-Slump of Fresh Grouts. The spreading ability of fresh grouts can be represented by mini-slump diameter, and the mini-slump test results are presented in Figure 6.
According to Figures 6(a) and 6(b), the addition of NC obviously decreased the mini-slump diameters at a W/S ratio of 1.2, and the increase in MFA content led to an increase in the mini-slump diameters of fresh grouts. When the NC contents were $0 \%, 0.5 \%, 1.0 \%$, and $2.0 \%$, the mini-slump diameters of fresh grouts (0\% SP) were 312-375, 295-350, 283-336, and 250-306 mm for MFA contents of $10-40 \%$. Furthermore, the addition of $1.5 \%$ SP significantly increased the mini-slump diameters. More specifically, the minislump diameters of fresh grouts (0-40\% MFA) with $1.5 \% \mathrm{SP}$ were $429-455,395-438,375-425$, and $342-403 \mathrm{~mm}$ when the NC contents were $0 \%, 0.5 \%, 1.0 \%$, and $2.0 \%$, respectively. Compared with fresh grouts without SP, the increasing effects of $1.5 \%$ SP on mini-slump diameters were $21.33-$ $37.5 \%, 25.14-33.90 \%, 26.49-32.51 \%$, and $31.70-36.80 \%$. The effects of NC, MFA, and SP on the spreading ability of fresh grouts were consistent with those on fluidity (apparent viscosity and flow time). The addition of MFA and SP can enhance the spreading ability, while NC had a negative impact on the spreading ability of fresh grouts.

3.6. Bleed Capacity. The bleed capacity is of major importance in grouting engineering because only stable grouts can ensure that microfractures are completely filled, while unstable grouts may lead to the partial filling of rock microfractures due to high bleeding. According to EN 12715, the fresh grout is characterized as stable when its bleed capacity is less than $5 \%$ after $120 \mathrm{~min}$ from preparation. The bleed capacity of fresh grouts with and without SP was measured, and the test results are shown in Figure 7.

As shown in Figures 7(a) and 7(b), the bleed capacity of fresh grouts decreased with increasing $\mathrm{NC}$ contents and increased with increasing MFA contents. The results indicated that the addition of NC can remarkably enhance the stability of fresh grouts. More specifically, when the NC contents were $0 \%, 0.5 \%, 1.0 \%$, and $2.0 \%$, the bleed capacity of fresh grouts $(0-40 \% \mathrm{MFA})$ without SP were $2.9-3.9 \%$, $2.5-3.5 \%, 2.2-3.1 \%$, and $1.8-2.9 \%$, respectively. However, the addition of $1.5 \%$ SP significantly increased the bleed capacity of fresh grouts, and the effects of SP on bleed capacity were obvious compared with those of MFA. Because the addition of SP can destroy the flocculated structure of grouts, the water in flocculated structure was released, and the bleed capacity of grouts was increased. The bleed capacity of fresh grouts with $1.5 \%$ SP were $4.2-6.7 \%, 3.9-6.2 \%$, $3.4-5.5 \%$, and $2.6-5.3 \%$ when the NC contents were $0 \%$, $0.5 \%, 1.0 \%$, and 2.0 , respectively. To obtain stable grouts, the contents of MFA should be controlled within $30 \%$.

3.7. Setting Time. The setting time of grouts need to be strictly controlled in grouting engineering because a short setting time may damage the grouting machine, while a long setting time leads to a slow construction schedule and reduces grouting efficiency. According to ASTM Standard C191, the initial and final setting times of grouts were measured on the sediments after water bleeding was negligible. The results of the initial and final setting times are presented in Figure 8. 


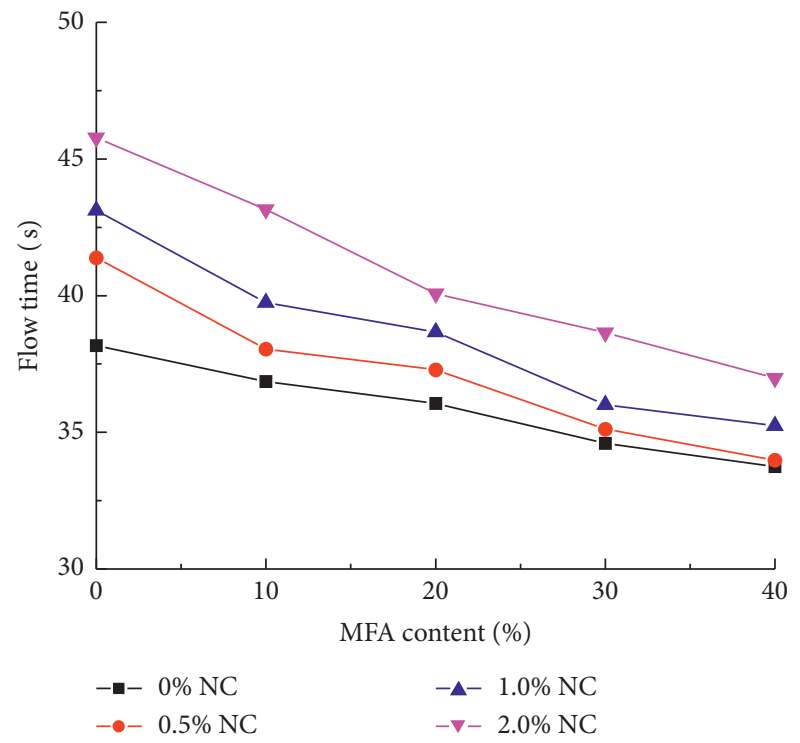

(a)

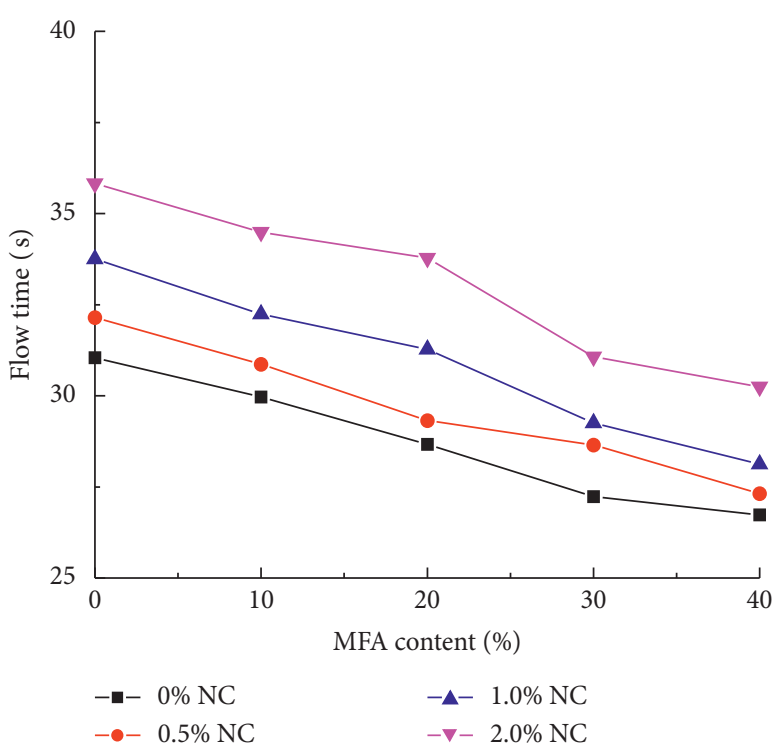

(b)

FIGURE 5: Flow times of fresh grouts with a W/S ratio of 1.2: (a) $0 \%$ SP; (b) $1.5 \%$ SP.

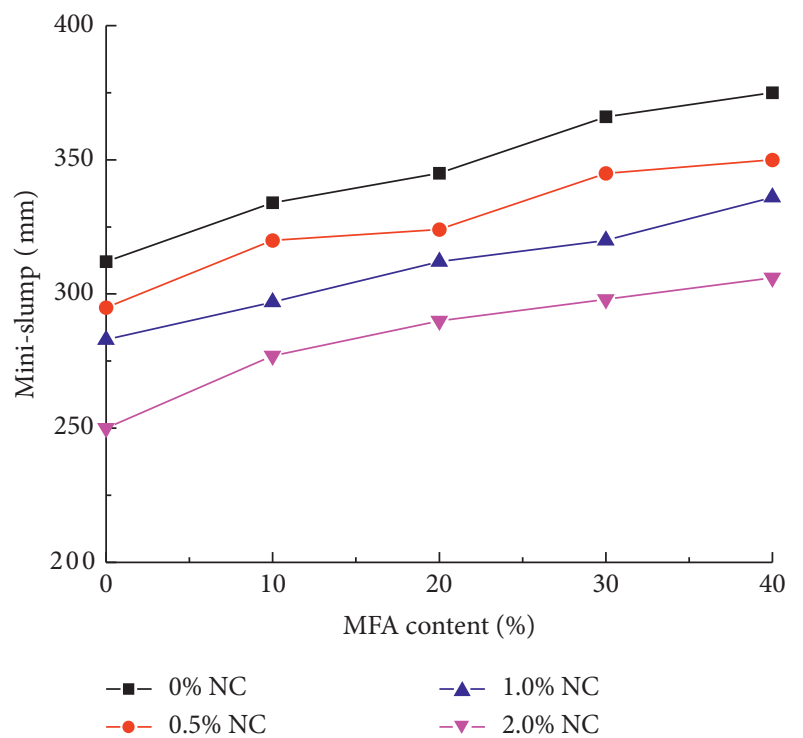

(a)

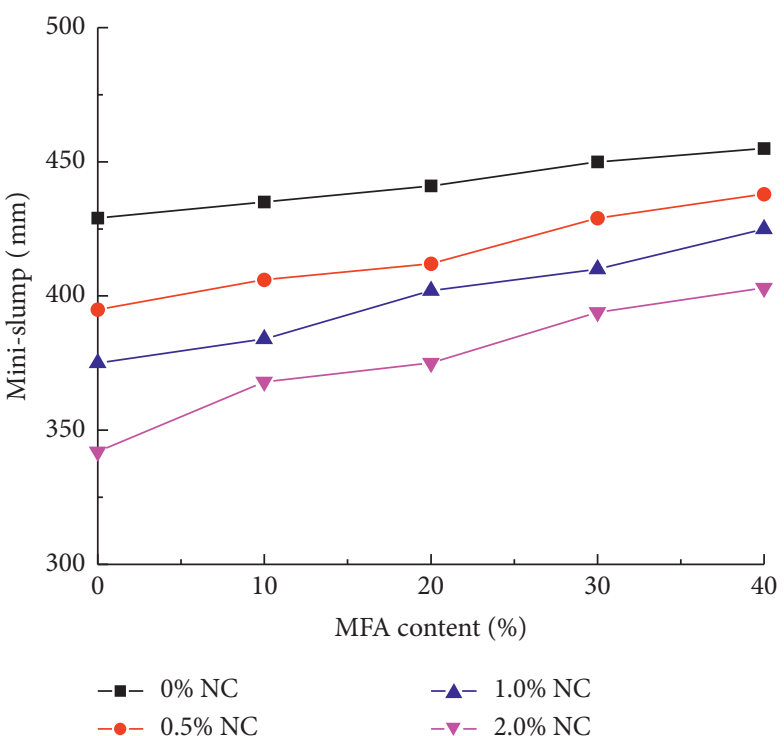

(b)

FIgURE 6: Mini-slump diameters of fresh grouts with a W/S ratio of 1.2: (a) $0 \%$ SP; (b) $1.5 \%$ SP.

As shown in Figure 8, the initial and final setting times of sediments decreased with increasing $\mathrm{NC}$ contents. When the amounts of NC were $0 \%, 1.0 \%$, and $2.0 \%$, the initial setting times of grouts $(0-40 \% \mathrm{MFA})$ were $6.1-8.3,5.2-7.9$, and $4.4-7.0 \mathrm{~h}$, respectively. The final setting times of the sediments were 10.8-13.6, 9.8-12.7, and 8.6-11.6 h, respectively. There are two probable factors that determine the effect of $\mathrm{NC}$ on setting time. First, NC particles have a large surface area and require more water; hence, the setting times of the grouts decrease. Second, the apparent viscosity might increase due to rapid depletion of the mixture water, and the solidification of grouts might start earlier [29]. However, the effects of MFA and SP on setting times were opposite to those of NC. The combination of MFA and SP was found to significantly prolong the setting times because the pozzolanic effect of MFA was slow in the early hydration process and the absorption of SP on the surface of MC particles slowed the early hydration process of $\mathrm{MC}$, thereby prolonging the setting times.

3.8. Flexural and Compressive Strength of Hardened Grouts. The 28-day flexural strengths of hardened grouts with $0 \%$ and 1.5\% SP are presented in Figure 9 for a W/S ratio of 1.2. 


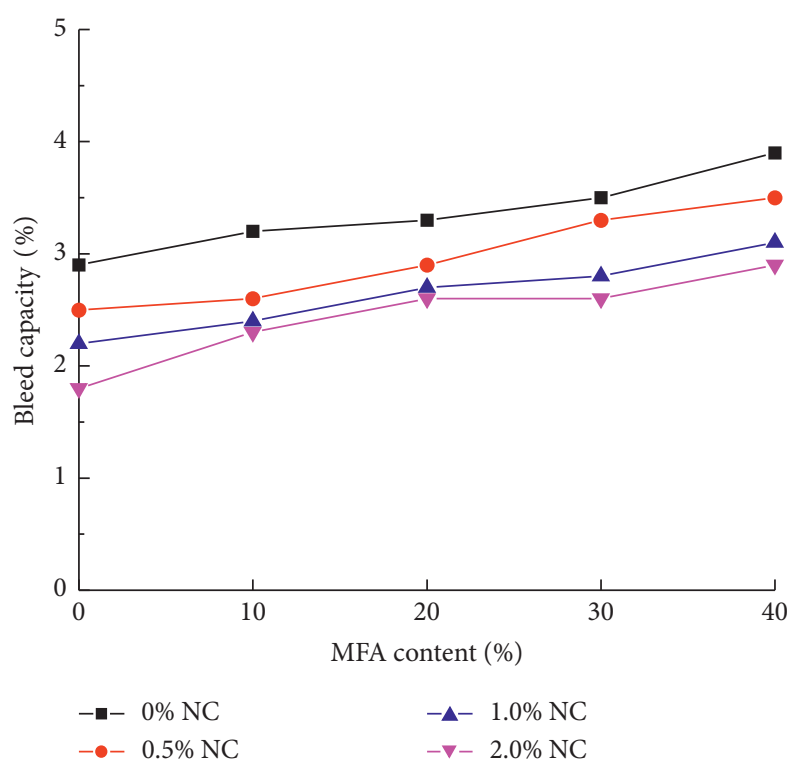

(a)

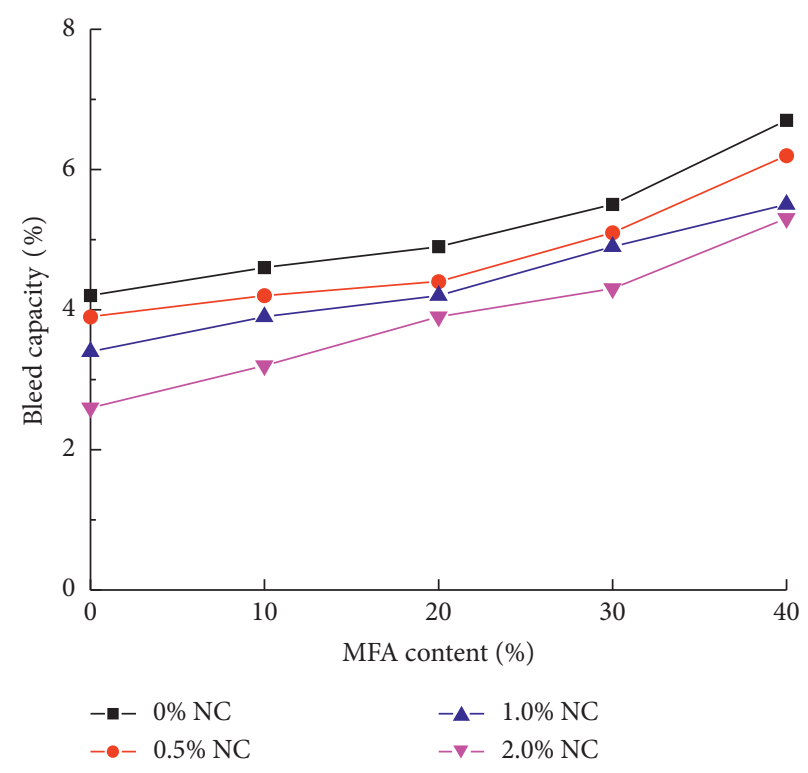

(b)

FIGURE 7: Bleed capacity of fresh grouts with a W/S ratio of 1.2 : (a) $0 \% \mathrm{SP}$; (b) $1.5 \% \mathrm{SP}$.

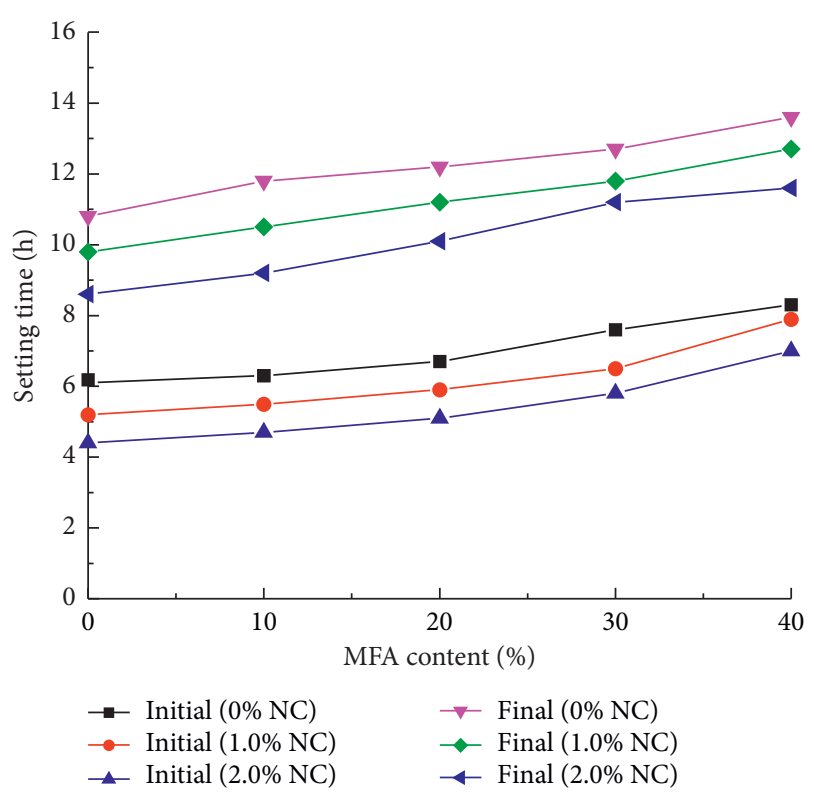

FIGURE 8: Setting times of fresh grouts with a W/S ratio of 1.2 and $1.5 \%$ SP.

As shown in Figure 9(a), the flexural strength of hardened grouts without SP increased slightly with increasing MFA contents. Moreover, the influence of NC on flexural strength was similar to that of MFA, but the increasing effect was more significant. When the contents of $\mathrm{NC}$ were $0 \%$, $0.5 \%, 1.0 \%$, and $2.0 \%$, the flexural strengths of hardened grouts (0-40\% MFA) without SP were 1.98-2.43, 2.12-2.56, 2.28-2.64, and 2.47-2.91 MPa, respectively. Figure 9(b) also reveals that the addition of $1.5 \%$ SP obviously increased the flexural strength of hardened grouts. The flexural strengths of hardened grouts with $1.5 \%$ SP were 2.56-3.18, 2.73-3.47,
3.28-3.71, and 3.39-3.83 MPa. Correspondingly, the increase degrees of $1.5 \%$ SP on flexural strength were $29.30-30.86 \%, 28.77-35.55 \%, 40.53-43.86 \%$, and $31.62-$ $37.25 \%$. This result may be attributed to the fact that $1.5 \%$ SP had a positive effect on raising the brittleness of hardened grouts and increasing the 28-day flexural strength.

Figure 10 shows the 28-day unconfined compressive strength of hardened grouts with $0 \%$ and $1.5 \%$ SP.

Figure 10(a) shows that the 28-day compressive strength of hardened grouts without SP decreased with increasing MFA contents and increased with increasing NC contents. This result was observed mainly because the addition of MFA decreased the concentration of hydration minerals such as tricalcium silicate, while the compressive strength development provided by the hydration of cement was greater than that provided by pozzolanic effects [30]. Moreover, for hardened grouts (10-40\% MFA) without NC and SP, the decreasing degrees of compressive strength were $3.87-17.02 \%$. However, for hardened grouts (10-40\% MFA) with $0.5 \%, 1.0 \%$, and $2.0 \% \mathrm{NC}$, the decreasing degrees of compressive strength were $4.37-13.05 \%, 4.05-12.23 \%$, and $1.05-10.18 \%$, respectively. Therefore, the addition of NC weakened the decreasing effect of MFA on the compressive strength of hardened grouts, which also indicated that the addition of NC can accelerate the hydration of MFA, which seemed to be helpful for cement with a large content of fly ash. Figure 10(b) shows that the addition of $1.5 \%$ SP decreased the compressive strength of hardened grouts. When the contents of NC were $0 \%, 0.5 \%, 1.0 \%$, and $2.0 \%$, the compressive strengths of hardened grouts (0-40\% MFA) with 1.5\% SP were 13.25-18.98, 14.31-19.87, 14.89-21.14, and 16.48-23.21 MPa, respectively. This phenomenon can be attributed to the fact that the addition of $1.5 \%$ SP inhibited the hydration process of cement and reduced the strength development of hardened grouts. 


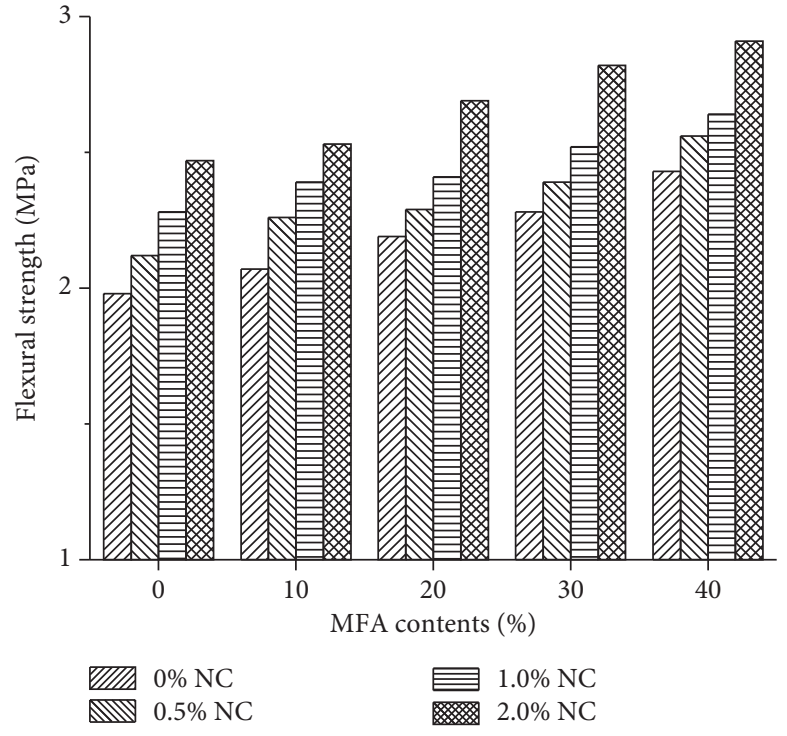

(a)

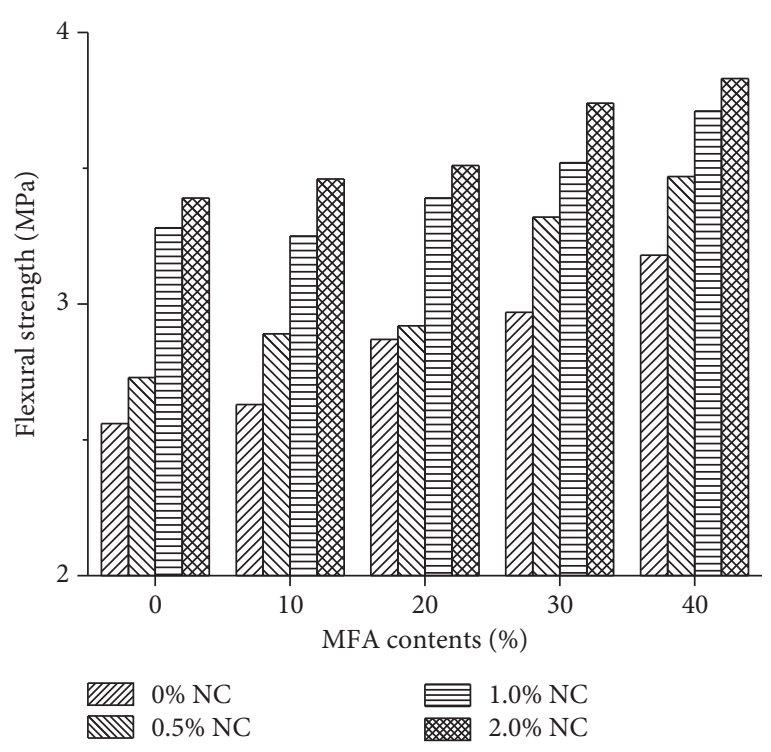

(b)

FIGURE 9: 28-day flexural strength of hardened grouts with a W/S ratio of 1.2: (a) $0 \%$ SP; (b) 1.5\% SP.

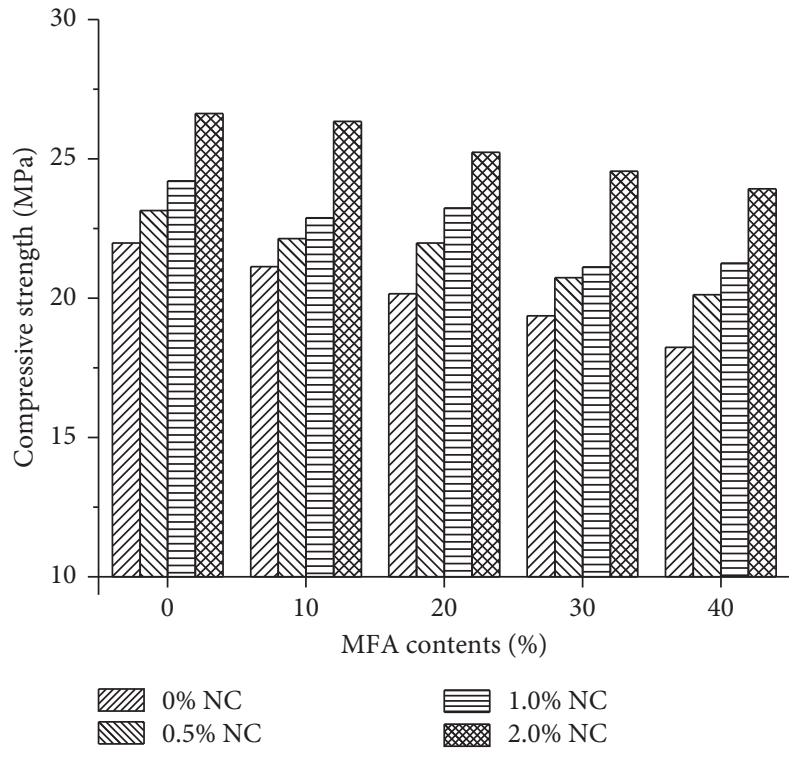

(a)

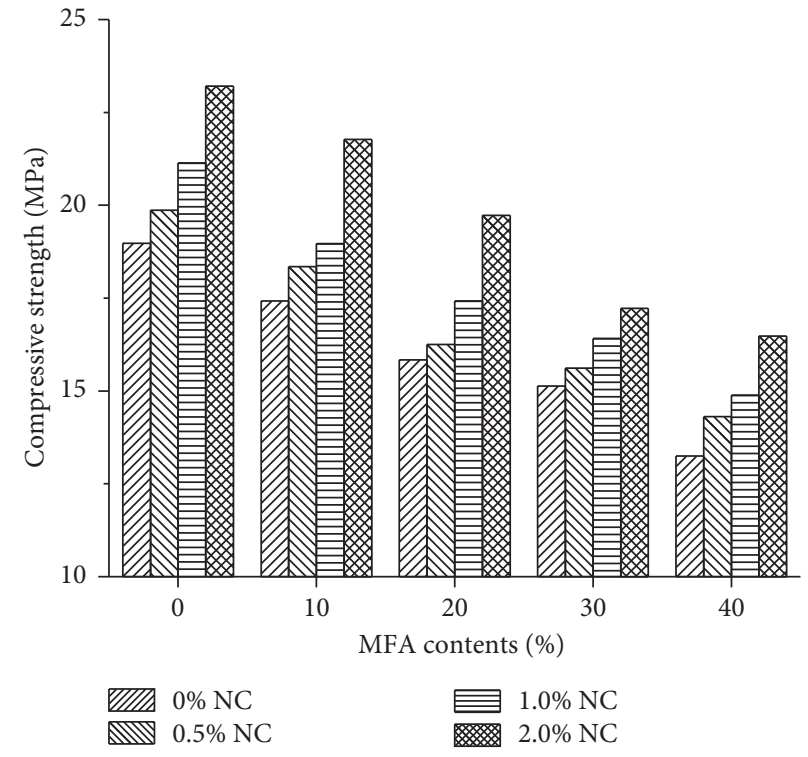

(b)

FIGURE 10: 28-day compressive strength of hardened grouts with a W/S ratio of 1.2 : (a) $0 \%$ SP; (b) $1.5 \%$ SP.

\section{Conclusions}

Based on the results obtained in this research, the following conclusions can be drawn:

(1) The addition of NC significantly affected the yield stress and plastic viscosity as a viscosity modifier, and the influence of NC is more remarkable on yield stress than on plastic viscosity. The fresh grouts with different NC contents in this research can be considered to behave as Bingham fluids, and the correlation coefficient was 0.99 in most cases.
(2) The performance of microfine-cement-based grouts is closely connected to the addition of MFA, NC, and SP. The fluidity (apparent viscosity and flow time) and spreading ability (mini-slump) are improved with increasing MFA and SP contents, while the bleeding and setting time are increased. Moreover, the increasing effects of $1.5 \% \mathrm{SP}$ on the mini-slump and bleeding are more obvious than those of MFA.

(3) The addition of NC decreases the fluidity and spreading ability of fresh grouts, although it can improve the stability and shorten the setting time. 
The compressive strength of hardened grouts is high compared with the flexural strength. The addition of MFA and SP had negative effects on the 28-day compressive strength. However, the 28-day compressive strength of hardened grouts increases with increasing $\mathrm{NC}$ content, probably because the seeding effect of the NC particles and the nucleation of CSH results in the strength enhancement of hardened grouts.

\section{Data Availability}

The data used to support the findings of this study are included within the article.

\section{Conflicts of Interest}

The authors declare that there are no conflicts of interest regarding the publication of this paper.

\section{Acknowledgments}

This research was funded by the National Key Research and Development Program, China (grant no. 2016YFC0600902), the National Natural Science Foundation of China, China (grant nos. 51474135, 51774192, and 51704183), and the Postgraduate Technology Innovation Project of Shandong University of Science and Technology (grant no. SDKDYC190239).

\section{References}

[1] I. N. Markou and A. I. Droudakis, "Factors affecting engineering properties of microfine cement grouted sands," Geotechnical and Geological Engineering, vol. 31, no. 4, pp. 1041-1058, 2013.

[2] M. Mollamahmutoglu and E. Avci, "Ultrafine portland cement grouting performance with or without additives," KSCE Journal of Civil Engineering, vol. 19, no. 7, pp. 2401-2050, 2015.

[3] I. A. Pantazopoulos, I. N. Markou, D. N. Christodoulou et al., "Development of microfine cement grouts by pulverizing ordinary cements," Cement and Concrete Composites, vol. 34, no. 5, pp. 593-603, 2012.

[4] M. Mollamahmutoglu and E. Avci, "Effectiveness of microfine portland cement grouting on the strength and permeability of medium to fine sands," Periodica Polytechnica Civil Engineering, vol. 59, no. 3, pp. 319-326, 2015.

[5] J. J. Assaad and N. Gerges, "Styrene-butadiene rubber modified cementitious grouts for embedding anchors in humid environments," Tunnelling and Underground Space Technology, vol. 84, pp. 317-325, 2019.

[6] A. J. Yang, P. Warwick, A. E. Milodowski, and D. Read, "Behaviour of radionuclides in the presence of superplasticizer," Advances in Cement Research, vol. 25, no. 1, pp. 32-43, 2013.

[7] S. C. Li, F. Sha, R. T. Liu, Z. F. Li, and Q. S. Zhang, "Investigation of viscous behaviour and strength of microfinecement-based grout mixed with microfine fly ash and superplasticizer," Advances in Cement Research, vol. 29, no. 5, pp. 206-215, 2017.
[8] F. Sha, S. C. Li, R. T. Liu, Z. F. Li, and Q. S. Zhang, "Experimental study on performance of cement-based grouts admixed with fly ash, bentonite, superplasticizer and water glass," Construction and Building Materials, vol. 161, pp. 282-291, 2018.

[9] A. Laichaoui, A. Zidol, R. Mitiche-Kettab, A. Bali, and A. Tagnit-Hamou, "Effect of the type of superplasticizer on the properties of cementitious systems incorporating slag," Journal of Adhesion Science and Technology, vol. 33, no. 2, pp. 187-207, 2019.

[10] M. Mollamahmutoglu and Y. Yilmaz, "Engineering properties of medium-to-fine sands injected with microfine cement grout," Marine Georesources \& Geotechnology, vol. 29, no. 2, pp. 95-109, 2011.

[11] J. Ren, Y. Lai, and J. Gao, "Exploring the influence of $\mathrm{SiO}_{2}$ and $\mathrm{TiO}_{2}$ nanoparticles on the mechanical properties of concrete," Construction and Building Materials, vol. 175, pp. 277-285, 2018.

[12] T. Sato and J. J. Beaudoin, "Effect of nano- $\mathrm{CaCO}_{3}$ on hydration of cement containing supplementary cementitious materials," Advances in Cement Research, vol. 23, no. 1, pp. 33-43, 2011.

[13] S. W. M. Supit and F. U. A. Shaikh, "Effect of nano- $\mathrm{CaCO}_{3}$ on compressive strength development of high volume fly ash mortars and concretes," Journal of Advanced Concrete Technology, vol. 12, no. 6, pp. 178-186, 2014.

[14] H. S. Yang and Y. J. Che, "Effects of nano- $\mathrm{CaCO}_{3} /$ limestone composite particles on the hydration products and pore structure of cementitious materials," Advances in Materials Science and Engineering, vol. 2018, Article ID 5732352, 8 pages, 2018.

[15] S. Sadrizadeh, A. Ghaffar, A. Halilovicc et al., "Numerical, experimental and analytical studies on fluid flow through a marsh funnel," Journal of Applied Fluid Mechanics, vol. 10, no. 6, pp. 1501-1507, 2017.

[16] R. M. Martins and A. J. F. Bombard, "Rheology of fresh cement paste with superplasticizer and nanosilica admixtures studied by response surface methodology," Materials and Structures, vol. 45, no. 6, pp. 905-921, 2012.

[17] F. Celik and H. Canakci, "An investigation of rheological properties of cement-based grout mixed with rice husk ash (RHA)," Construction and Building Materials, vol. 91, pp. 187-194, 2015.

[18] J. J. Assaad and Y. Daou, "Cementitious grouts with adapted rheological properties for injection by vacuum techniques," Cement and Concrete Research, vol. 59, pp. 43-54, 2014.

[19] S. Gopinathan and K. B. Anand, "Properties of cement grout modified with ultra-fine slag," Frontiers of Structural and Civil Engineering, vol. 12, no. 1, pp. 58-66, 2018.

[20] Y. Zhang, Q. Zhao, C. Liu, and M. Zhou, "Properties comparison of mortars with welan gum or cellulose ether," Construction and Building Materials, vol. 102, pp. 648-653, 2016.

[21] C. A. Anagnostopoulos, "Effect of different superplasticisers on the physical and mechanical properties of cement grouts," Construction and Building Materials, vol. 50, pp. 162-168, 2014.

[22] ASTM International, ASTM C191-13, Standard Test Methods for Time of Setting of Hydraulic Cement by Vicat Needle, ASTM International, West Conshohocken, PA, USA, 2013.

[23] Standardization Administration of the People's Republic of China, GB/T. 17671 Method of Testing Cements-Determination of Strength, Standardization Administration of the People's Republic of China, Beijing, China, 1999. 
[24] ASTM International, ASTM C78/C78M-16, Standard Test Method for Flexural Strength of Concrete (Using Simple Beam with Third-Point Loading), ASTM International, West Conshohocken, PA, USA, 2016.

[25] International Organization for Standardization, ISO13320-1, Particle Size Analysis-Laser Diffraction Methods-Part 1 General Principles, International Organization for Standardization, Geneva, Switzerland, 1999.

[26] S. Perret, D. Palardy, and G. Ballivy, "Rheological behavior and setting time of microfine cement-based grouts," ACI Materials Journal, vol. 97, no. 4, pp. 472-478, 2000.

[27] A. C. El ldrissi, E. Roziere, A. Loukili, and S. Darson, "Design of geopolymer grouts: the effects of water content and mineral precursor," European Journal of Environmental and Civil Engineering, vol. 22, no. 5, pp. 628-649, 2018.

[28] Q. Wang, J. Wang, C.-X. Lv, X.-Y. Cui, S.-Y. Li, and X. Wang, "Rheological behavior of fresh cement pastes with a graphene oxide additive," New Carbon Materials, vol. 31, no. 6, pp. 574-584, 2016.

[29] F. U. A. Shaikh and S. W. M. Supit, "Mechanical and durability properties of high volume fly ash (HVFA) concrete containing calcium carbonate $\left(\mathrm{CaCO}_{3}\right)$ nanoparticles," Construction and Building Materials, vol. 70, pp. 309-321, 2014.

[30] S. Zhang, W. G. Qiao, P. C. Chen, and K. Xi, "Rheological and mechanical properties of microfine- cement-based grouts mixed with microfine fly ash, colloidal nanosilica and superplasticizer," Construction and Building Materials, vol. 212, pp. 10-18, 2019. 


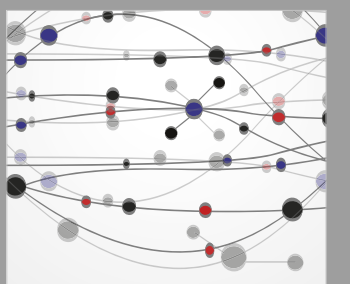

The Scientific World Journal
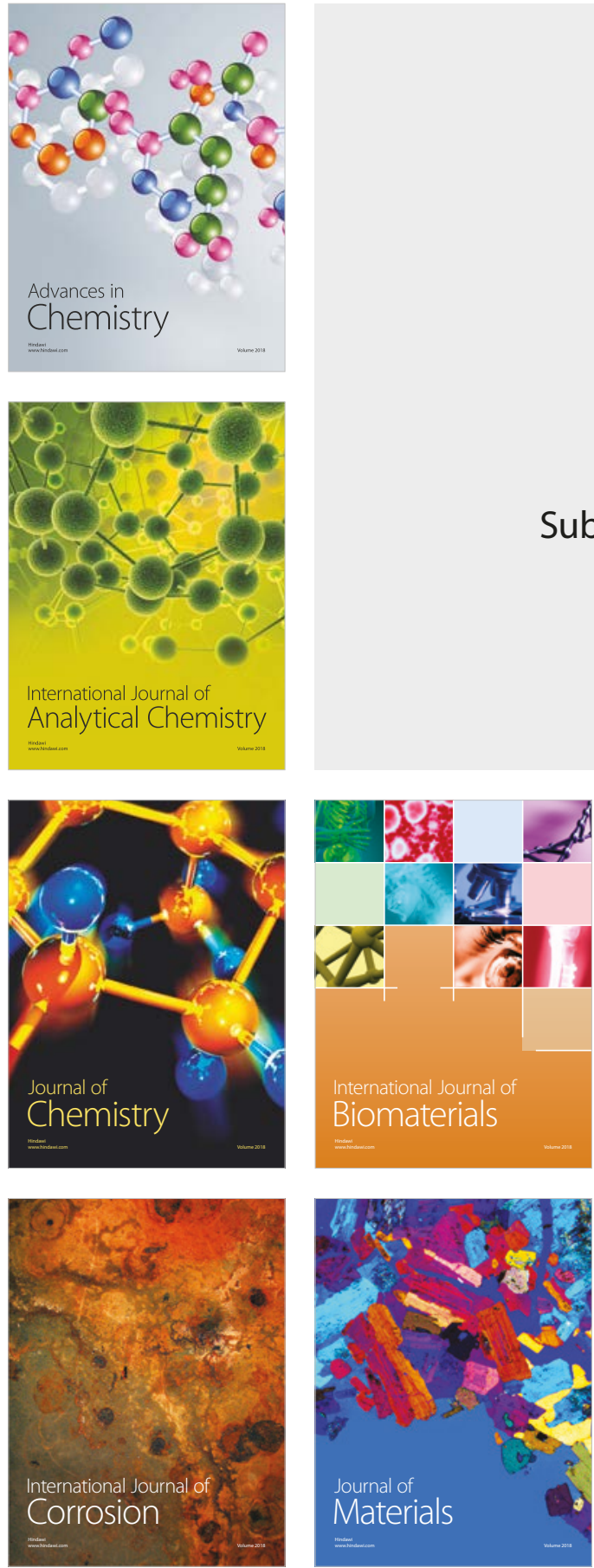

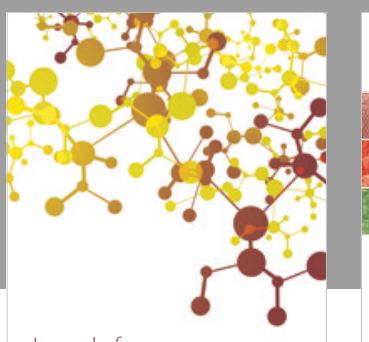

Journal of

Applied Chemistry
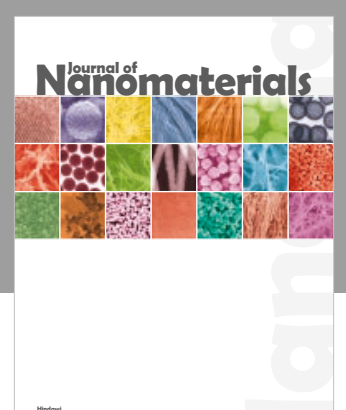

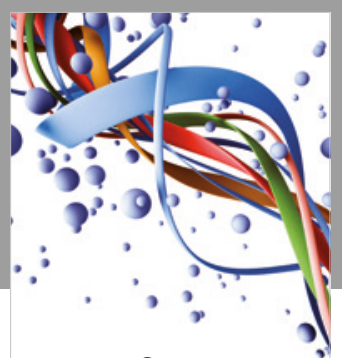

Scientifica

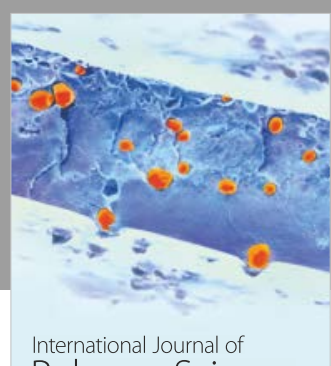

Polymer Science

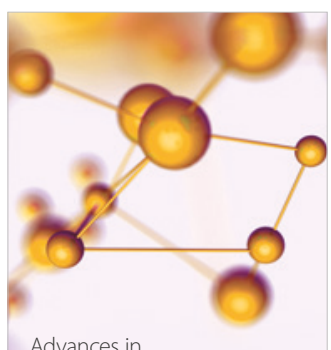

Physical Chemistry
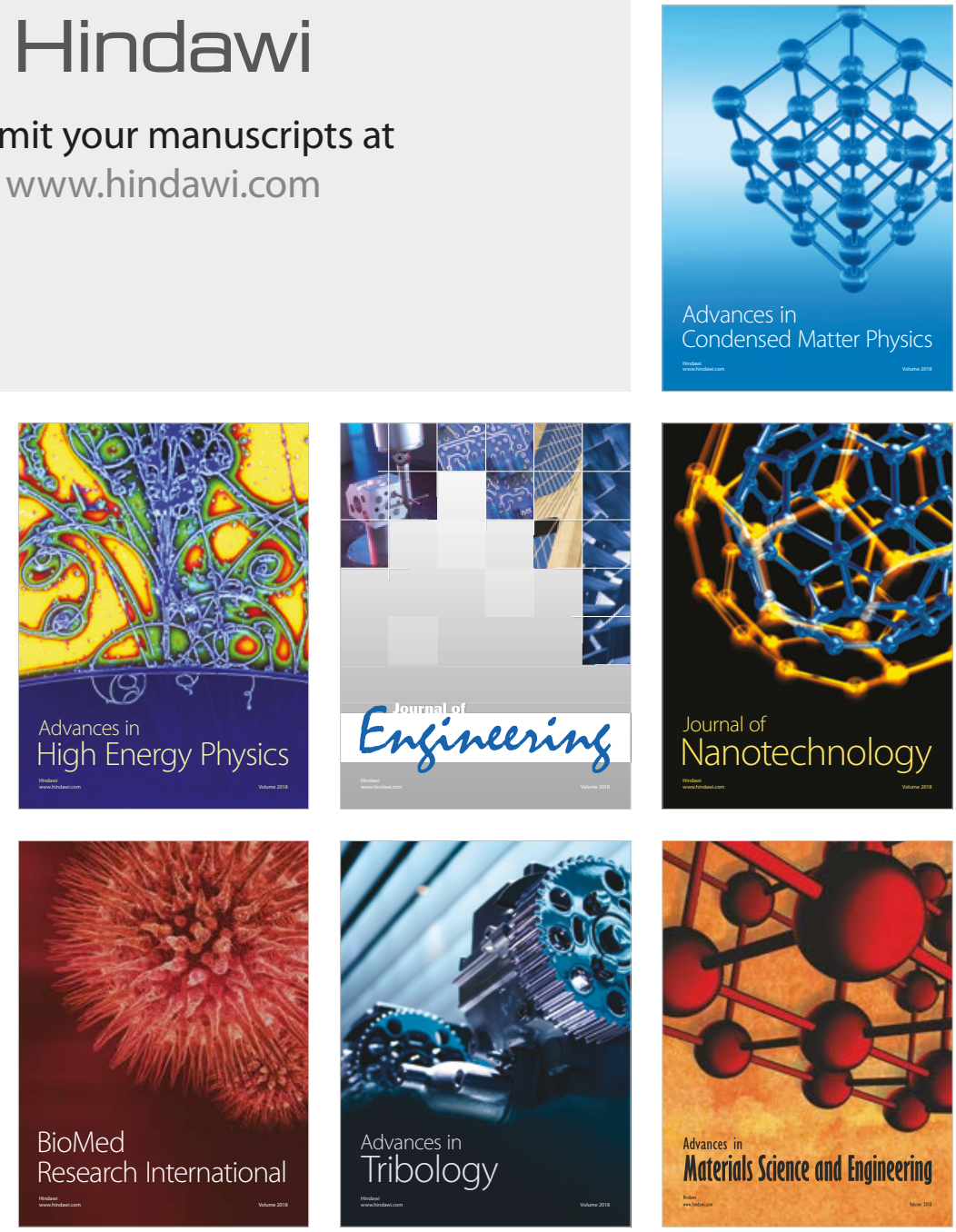